\title{
VITAMIN D DEFICIENCY IN CHILDREN LIVING IN JEDDAH, SAUDI ARABIA
}

\author{
M.M. Hamdi ${ }^{1,2}$, K.M. Al Hadidi ${ }^{3,4}$
}

${ }^{1}$ Pediatrics, Cairo University, Cairo, Egypt, ${ }^{2}$ Pediatrics, Jeddah Clinic Hospital, Jeddah, Saudi Arabia,

${ }^{3}$ Clinical Pathology, Ain Shams University, Cairo, Egypt, ${ }^{4}$ Clinical Pathology, Jeddah Clinic Hospital, Jeddah, Saudi Arabia

Background: Vitamin D deficiency is an unrecognized epidemic and a common health problem worldwide.

Methods: This study was conducted in the pediatric clinic in Jeddah Clinic Hospital-Kandarah from April through December 2010 . 510 healthy children aged 4 to15 years old were enrolled. Serum 25hydroxyvitamin D (25-OHD) wasmeasured. Dietary vitamin D intake, duration of daily sunlight exposure were determined. 25-OHD levels $<20 \mathrm{ng} / \mathrm{mL}$ and $<7 \mathrm{ng} / \mathrm{mL}$ were defined as relative and severe vitamin D deficiency, respectively.

Results: The mean concentration of $25(\mathrm{OH}) \mathrm{D}$ was $13.07 \pm 7.81 \mathrm{ng} / \mathrm{mL}$

70 subjects $(13.72 \%)$ had normal 25(OH)D level . $300(58.82 \%)$ had relative $25(\mathrm{OH}) \mathrm{D}$ deficiency and 140 $(27.45 \%)$ had severe deficiency $(P=0.000) .220(43.14 \%)$ were males and $290(56.86 \%)$ were females having a statistical significant difference in the incidence of $25(\mathrm{OH}) \mathrm{D}$ deficiency $(P=0.019)$. Saudis and Yemenis were more subjected to $25(\mathrm{OH}) \mathrm{D}$ deficiency in comparison to Egyptians and other nationalities $(P=0.01)$. there were significant inverse correlations between 25 -hydroxyvitamin $\mathrm{D}$ levels and both body weight and height $(P=0.000)$. There was a significant correlation between bony aches and $25(\mathrm{OH}) \mathrm{D}$ deficiency $(P=0.000)$. Duration of sunlight exposure and daily intake of vitamin D had significant effects on serum level of vitamin D.

Conclusions: A high prevalence of vitamin D deficiency in children living in Jeddah was observed in this study. Routine screening for vitamin D status should be done for all children. Further studies including larger number of subjects are recommended for proper evaluation and management of this problem. 